\title{
Communicative Language Teaching: Do Tasks and Activities in School Textbooks Facilitate Learners' Development of Communicative Competence?
}

\author{
Cang Trung Nguyen \\ Foreign Languages Faculty, Kien Giang University, Kien Giang, Vietnam \\ Diem Thi Kieu Le \\ Testing and Quality Assurance Department, Kien Giang University, Kien Giang, Vietnam
}

\begin{abstract}
This paper reports a theoretical evaluation and findings from teachers' and students' evaluations of activities and tasks in English 6, an English textbook from a series of four textbooks which have been used as the compulsory textbooks for all students from grades 6 to 9 (ages 12 to 16) in all junior secondary schools in Vietnam since 2001 (Nguyen, 2005). It presents results from a study which involved 8 teachers and 126 students in four secondary schools in the Mekong Delta, Vietnam. Combining a theoretical evaluation and the analysis of the data collected from the questionnaires, semi-structured interviews and classroom observation. It is concluded that there is a lack of a variety of activities and tasks and they mostly focus on form. Therefore, they do not help develop learners' communicative competence. The present study also draws implications regarding how to use teaching materials effectively for EFL/ESL for developing learners' communicative competence.
\end{abstract}

Index Terms - evaluation of English 6, English 6 evaluation, textbook evaluation

\section{INTRODUCTION}

The previous research studies on textbook evaluation have shown that activities and tasks in textbooks can help promote learner interaction which is considered to have more benefits than teacher-fronted whole class instruction (Litz, 2006). Long (1990) indicates five benefits students have in student-student interaction. These include: the increase the quantity of students' language use, the improvement of the quality of students' language use, more opportunities to individualize instruction, a less threatening language use environment and the enhancement of motivation for learning. Unfortunately, Jacobs and Ball (1996) complain that in many textbooks, in order to help make learner interactions, the authors put the words 'in groups' or 'in pairs' in front of many activities which should be individual activities to try to encourage learners to cooperate with one another. Such activities just work in very few situations, but for effective interactions to take place according to them 'students will generally need more guidance and encouragement' not just simple instructions and requirements before the tasks and activities (Jacobs \& Ball, 1996, p. 99).

Given that second language learners need activities and tasks which help them practice and perform the target language well in both inside and outside of the classroom, this study investigates the real communicative practice through activities and tasks via English 6 with a hope that it can propose implications for both textbook designers and teachers who are using and will be using the textbook. It is part of an overall textbook evaluation project for English 6 . It especially focuses on (1) what kinds of activities and tasks are included in the textbook, (2) to what extent they help encourage learner interaction and promote learners' communicative abilities and (3) what the instructors and learners suggest for improvement.

\section{LITERATURE REVIEW}

\section{A. Textbook Evaluation}

Textbook evaluation is a process of measuring the value or potential value of textbooks (Tomlinson, 2003). According to this definition, it involves making judgments about the effects of textbooks on people (learners, instructors and administrators) who use them. These effects may involve many criteria such as: the credibility, validity, flexibility, etc. of the textbooks. To share this point of view on textbook evaluation, Rea-Dickins and Germanie (1994) define evaluation 'as the means by which we can gain a better understanding of what's effective, what's less effective and what appears to be no use at all' (p. 28). 
Lynch (1996) defines evaluation as 'the systematic attempt to gather information in order to make judgments or decisions' (p. 2). Weir and Roberts (1994) seem to be more specific when they consider textbook evaluation to be a systematic collection and analysis of all relevant information necessary to promote the improvement of the textbook and access its effectiveness and efficiency. Nevo (1977) supports Weir and Robert's view, adding that:

Evaluation refers to the process of delineating, obtaining and providing information on the merit of goals, designs, implementation and outcomes of educational activities, and should help to improve educational activities, and should help to improve an educational product during the process of its development, and/or demonstrate the merit of the final product when its development is completed. (Nevo, 1977, p. 127 as cited in Nguyen, 2015: 34)

To suit the teaching and learning context in this study, Nguyen (2015) mentions, textbook evaluation could be defined as the process of collecting information about a textbook and analyzing it to find out what works well, the merits, and what needs complementing, balancing or ruling out, the deficiencies, in order to make sound decisions and judgments to use the textbook efficiently for a particular course of instruction.

\section{B. Evaluation of Activities and Tasks}

The evaluation of activities and tasks is important. It aims to find out whether there is a variety of activities and tasks in a textbook which will meet learners' interests, needs and learning styles. It is also suggested that the activities and tasks should reflect topics and texts from real world situations and be challenging enough to gain the learners' attention (Tomlinson, 2003). The most important point is that the activities and tasks should be graded relevantly to help the process of second language acquisition happen comfortably. Another characteristic of good activities and tasks in a textbook is that there should be form-focused tasks, meaning-focused tasks as well as both form- and meaning-focused tasks in certain periods of lessons to interest learners. It is essential for a textbook to include different kinds of activities such as pair work activities, group work activities and individual work activities and these activities should tend to develop both the learners' language use and skills.

To evaluate activities and tasks in a textbook effectively, Crookes and Gass (1993) suggested that the most effective tasks and activities should be those which promote the greatest opportunities for learners to experience comprehension of input, feedback on production and inter-language modification. These can be information gap activities, jigsaw activities, problem solving, decision making, and opinion exchange, Nguyen (2015).

In order to effectively involve learners in activities and tasks which may lead to success in language learning, the activities and tasks in a textbook should be designed to

- develop four language skills and communicative abilities,

- encourage learner interaction in classroom,

- develop learner autonomy in learning,

- and give clear instructions.

(Nguyen, 2015).

Developing four language skills and communicative abilities is a pivotal characteristic which needs to be explicitly expressed in activities and tasks. A good balance between receptive skills (listening and reading) and productive skills (speaking and writing) in the activities and tasks is required in each textbook in ELT to make sure the four language skills are practiced equally. It is suggested that the activities designed for learners to practice separate skills should tend to develop their communicative abilities. It means that there are activities and tasks in which learners can exchange information and communicate ideas and talk not just for practicing language as required but for sharing ideas, cooperating towards a certain goal, and competing to attain their goals (Crookes \& Gass, 1993).

There should be activities and tasks which require learners to practice each skill separately and there should be integrated ones in which more than one skill are required to be practiced simultaneously, to draw learners' interest and facilitate their classroom communication.

Encouraging learner interaction in the classroom is another important issue to evaluate activities and tasks in a textbook. Interaction, according to Thomas (1987) is 'acting reciprocally, acting upon each other' (p. 7). In his definition, he pointed out that action and reaction may not be interaction; in order to become interaction they need to be reciprocal. It means interaction is mutual influence or exchange of interlocutors. Learner interaction in this study is defined as the way in which learners exchange ideas or information to fulfill a task in their classroom. Encouragement of learner interaction helps learners interact to complete a task.

The promotion of learners' communicative abilities is closely connected with learner interaction in classroom activities and tasks. According to Canale (1983) "communicative competence includes four components: grammatical, socio-linguistic, discourse and strategic competence' (cited in Nguyen, 2013: 857). Chomsky (1965, as cited in Nguyen, 2013: 857) states that "grammatical competence is a language competence which reflects the knowledge of vocabulary; rules of word formation; pronunciation and spelling; and sentence formation". Socio-linguistic competence is the appropriateness of language use in social contexts (Hymes, 1979). Discourse competence is ' $\ldots$ an understanding of how spoken and written texts are organized and how to make inferences which cover the underlying meaning of what has been said and the connection between utterances' (Skehan, 1998, p. 158). Lastly, "strategic competence or compensatory competence is used when other competences fail to cope with the situations such as lack of words or structures in communication" (Canale \& Swain, 1980 as cited in Nguyen, 2013: 857). 
The value of student-student interaction to promote learning in classroom activities is advocated by many theorists such as Long (1990) and McDonough and Shaw (1993). Long (1990) points out five benefits of student-student interactive activities as follows:

- increased quantities of students' language use;

- enhanced quality of the language students use;

- more opportunities to individualize instruction;

- a less threatening environment in which the language is used;

- and greater motivation for learning.

Jacobs and Ball (1996) mention that the best types of activities for effective interactions are those in which learners can negotiate meaning or those that promote positive interdependence and individual responsibility in learning cooperation. Among the two given types of activities, the former is explained to be an action taken in order to ensure that all members in groups have communicated successfully. The latter, however, exists only when learners feel that there is a strong link between them and other members in their group, they cannot be successful if their group cannot and vice-versa so they have to cooperate with other members in their group for the success and completion of a task. The most important point at this stage is how to assess an individual's performance to ensure all members have worked and had their contribution recognized to avoid some doing everything and some doing nothing, which can discourage some from participating in the activities (Jacobs \& Ball, 1996).

Real language communication is emphasized in each activity and task, as it is not just about practicing language in the situations under the control of teachers or the materials given, but in situations in which learners can decide the content, strategies and expression of the interaction. This helps learners develop their own strategic competence and check their own effectiveness of their own internal hypotheses (Tomlinson, 1998). Real communicative interaction in classroom, according to Tomlinson (1998) can be achieved through:

- Information or opinion gap activities which require learners to communicate with each other and/or the teacher in order to close the gap (e.g. finding out what food and drink people would like at the class party);

- Post-listening and post-reading activities which require the learners to use information from the text to achieve a communication purpose (e.g. deciding what television programs to watch, discussing who to vote for, writing a review of a book or film);

- Creative writing and creative speaking activities such as writing a story or improvising a drama;

- Formal instruction given in the target language either on the language itself or on another subject. (Tomlinson, 1998, p. 15)

Developing learner autonomy and independence should be clearly indicated in activities and tasks. Learner autonomy here is defined as the learners' ability to take charge of their own learning (Cotterall, 2000). To put it in other words, it is a way to make learners aware of their own study. Autonomous learning, according to Mishan (2005), helps learners return to their earliest experiences in language learning as 'L1 acquisition is essentially an autonomous process' (p. 36). It also conforms to the concept that 'we are born, self-directed learners' (Benson, 2001, p. 59). Developing learner autonomy and independence is to develop the learners' ability and attitude for self-study, lifelong study and steady independence from teachers.

Promoting learner autonomy and independence is important, as teachers are not always available to assist learners at all times. Moreover, 'learners become more efficient in their language learning if they do not have to spend time waiting for the teacher to provide them with the resources or solve their problems' (Cotterall, 1995). In order to foster learner autonomy, the activities and tasks in the textbook should be designed to raise learners' awareness of 'ways of identifying goals, specifying objectives, identifying resources and strategies needed to achieve goals, and measuring progress.' (Kenny, 1993, p. 111).

Learner awareness-raising is revealed within activities and tasks and after each lesson. According to Cotterall (2000), within activities and tasks learners should be asked the questions such as: 'Why are we doing this? How will it help? What makes it difficult?' and after each lesson such questions as: 'What did you do today? What did you learn today? What are you going to do differently as a result of today's class?'.

According to the above-mentioned characteristics about learner autonomy, it is essential that textbooks should be learner-centered, so that learners are decision-makers about their own learning. Activities and tasks should encourage learners to learn independently and exploit their prior knowledge and experience to guess, predict, discover and take risk. Developing learner autonomy and independence also means that learners are introduced to activities and tasks which involve them in thinking about the learning process and experiencing different types of learning activities. Through the activities and tasks they can discover their own learning styles and strategies (Tomlinson, 2003).

Another important point relevant to developing learner autonomy and independence is that tasks, activities and exercises should enable students to monitor and measure their own progress. The progress monitoring and measuring can be achieved through activities and tasks which require learners 'to reflect on their learning, such as discussion of the goal-setting process, analysis of task types, and experimentation with strategies.' (Cotterall, 2000, p. 115).

\section{METHODOLOGY}

\section{A. Research Context and General Description of the Textbook}


This research was conducted in four junior secondary schools in the Mekong Delta - Vietnam, which is considered to have a textbook-based teaching and learning education system (Duggan, 2001). To put it in other words, it is a system in which all teachers have to use a compulsory teaching and learning textbook and follow a very detailed and rigid instructional framework issued by the MOET with the annual adjustments (if any) from the provincial Departments of Education and Training for each subject officially taught at schools, especially in general education (grades 1 to 12). In such an education system, the role of textbooks becomes more important and the requirement of following the textbooks and the detailed instructional framework seems to be a paramount factor for teachers to fulfill their duty. Moreover, Mekong Delta is considered to be the lowland of the country in education with large population, distinctive geographical conditions and lifestyles. In such a particular language teaching and learning context, the researcher carried out this research to find out what works well and what needs improving to make English $\mathbf{6}$ better suited to the language teaching and learning environment there.

English 6 was first published in 2001, now all junior secondary schools use the $4^{\text {th }}$ edition version. It consists of 204 pages with 16 units long. Each unit has two or three sections corresponding to a topic and they are closely related to each other. It is accompanied by a teacher's manual, a students' workbook, a cassette tape and a set of pictures as teaching aids. It is intended for $6^{\text {th }}$ grade (aged 12) students who start to study English. According to Nguyen (2015), it is taught in 105 forty-five-minute periods in the classroom. It is claimed to be theme-based, consisting of the communicative topics closely related to students' needs and hobbies. The language material is introduced to students and practiced through situations and exciting activities which help promote students' creative roles in study. It helps encourage communicative activities as well as master the grammatical structures to make a good prerequisite for language competence development.

\section{B. Participants, Data Collection and Data Analysis}

\section{Participants}

Eight teachers and 126 students who were using the textbook in $(2016$ - 2017) school year in four different junior high schools in four different provinces (Kiengiang, Haugiang, Angiang and Camau) in Mekong Delta, Vietnam participated in the research. The four schools and four provinces were chosen because they are typical areas in Mekong Delta with the diversity of ethnic minorities (Khmer, Cham) and geographical and economic conditions (borderline and island areas).

Eight teachers ( 7 female; 1 male) ranging from twenty-five to fifty years of age and from two to twenty-five years of experience in ELT at junior secondary schools and 126 students ( 75 female; 51 male) at similar ages from twelve to thirteen participated in the study.

These participants were chosen based on the introduction and permission from the head teachers of the schools where the research was conducted.

\section{Data collection}

As this research study involves human subjects, approval from the four Departments of Education and Training (DoET) had to be obtained. Prior to the start of this study, I sent letters to the directors of the (DoET) of the four abovementioned provinces, seeking their permission to conduct this research in some state schools in the study areas. Before conducting the study at each school, the researcher contacted the school head teacher to seek verbal permission to undertake the research, and to access the relevant staff and students needed for the research study. It also allowed me to make arrangements to meet the English teaching staff, in order to talk to them about the research plan and to seek voluntary participants (Nguyen, 2015).

Questionnaires were delivered to both the teachers and students by the researcher. There were two different sets of questionnaires, one for teachers and the other for students. They were designed to collect data from the instructors and students and they consisted of both close- and open- ended questions. The questions in the questionnaires for both the instructors and students aimed to investigate their opinions and suggestions on the activities and tasks in the textbook. The questions covered the following issues: the suitability of the activities and tasks for students' level, the instructions given before the activities and tasks, the distribution of the four language skills and the suggestions for improvement.

All of the teachers were also asked to take part in semi-structured interviews after the completion of the questionnaires. The questions in the interviews with the instructors were open-ended and focused on the same issues as the questions in the questionnaires as their aim was to make the results more reliable. Each interview lasted from twenty to thirty minutes.

In addition to the above data, eight 45-minute periods of classroom observation taught by the eight teachers were conducted and audio-recorded. In order to make the result of the observation more objective, I did it with the help of two other teachers whom I invited at each school. The two teachers were given the lesson observation sheet and some guidelines about what to take note during the lesson from me before observing the lesson (Nguyen, 2015). I also told the teachers who did the demonstration teaching the purpose of it carefully to make sure they would carry out the lesson in the similar way they do every day. After each classroom observation, I organized a meeting with the two teachers having attended it to discuss and make a final consensus about the lesson based on the criteria given on the lesson observation sheet.

\section{Data analysis}


In the questionnaires, data was analyzed by listing all raw data (all the individual responses) under each question, and then grouping the similar responses, identifying common themes, and counting frequencies.

However, analyzing interviews, according to Patton (1990), there are two strategies: case analysis and cross-case analysis. Implementing case analysis means writing a case study for each person interviewed. Using cross-case analysis means grouping together answers from different people to common questions or analyzing and grouping different perspectives on central issues. In this study, interviews were analyzed by using cross-case analysis, for the data obtained from the interviews it was better and more easily integrated to the data from other sources such as questionnaires. The data collected from the semi-structured interviews were analyzed by grouping the similar responses together and identifying common themes and counting the frequencies (Nguyen, 2015).

In the classroom observation, classroom size, layout and real equipment were described. Common stages of lesson conducting among the eight periods were recognized, grouped together and analyzed (Nguyen, 2015). Illustrations of typical stages of teachers' conducting specific lessons were given. Similar results of the consensus among the observers in specific aspects of classroom observation of the eight periods were group together for analysis.

\section{Findings: TheORETiCAl Evaluation}

\section{A. Types of Activities and Tasks Introduced in the Textbook}

The findings, when looking generally at the activities and tasks in English 6 indicate that it does not provide learners with a variety of activities and tasks. It mostly consists of individual work and pair work activities. In the textbook, according to Nguyen (2015), there are many form-focused activities (i.e., controlled practice which focuses on the use of a structure or a grammar point such as repetition and substitution drills) but not many meaning-focused or form- and meaning-focused tasks (i.e., free practice in which learners can exchange information and ideas or use their own information and ideas to practice with other students such as write sentences about your place or practice with a partner about his/her daily activities) (see Table 1). Most of the lessons usually begin with a rather easy activity 'Listen and repeat' then 'Practice' in pairs, they end with a writing activity or task named 'Write' considered to be a little bit more difficult and this recurs in each lesson across the textbook (see Table 1 below).

TABLE 1

RANGE OF ACTIVITIES AND TASKS PRESENTED IN ENGLISH 6

\begin{tabular}{|l|l|l|l|l|l|l|l|l|l|l|l|l|l|l|l|l|l|}
\hline \multirow{2}{*}{ Types of activities and tasks } & \multicolumn{9}{|c|}{ Lesson } & \multicolumn{1}{|c|}{} \\
\hline & 1 & 2 & 3 & 4 & 5 & 6 & 7 & 8 & 9 & 10 & 11 & 12 & 13 & 14 & 15 & 16 & Totals \\
\hline 1. Listen and repeat & 7 & 2 & 3 & 4 & 3 & & 3 & 1 & 4 & 4 & 1 & 3 & 2 & & 3 & 2 & 42 \\
\hline 2. Practice & 2 & & 2 & & & & & & & & & & & 1 & & & 4 \\
\hline 3. Practice with a partner & 3 & 1 & 3 & 1 & 1 & 2 & 1 & & 3 & 2 & & 1 & 1 & & 1 & 1 & 21 \\
\hline 4. Practice with a group & 1 & & & & & & & & & & & & & & & & 1 \\
\hline 5. Write in your exercise book & & 1 & & & & & & & & & 1 & & & & & & 2 \\
\hline 6. Remember & 3 & 3 & 3 & 3 & 3 & 3 & 3 & 3 & 2 & 3 & 2 & 3 & 2 & 3 & 3 & 2 & 44 \\
\hline 7. Game & 2 & 2 & 1 & 1 & & 2 & 1 & 3 & 1 & 1 & & & & & & 1 & 15 \\
\hline 8. Match and write & & 1 & & & & & & & & 1 & & & & & & & 2 \\
\hline 9. Listen and repeat. Then practice with a partner & & 4 & 1 & 2 & 3 & & & & & 5 & 3 & & 1 & 4 & & & 23 \\
\hline 10. Answer the questions & & & 2 & 3 & 2 & 1 & & 3 & & 2 & 1 & 1 & & 3 & 2 & 1 & 21 \\
\hline 11. Listen and read. Then answer the questions & & & 1 & & & 3 & 2 & 2 & 2 & & 1 & 2 & & & 4 & 3 & 20 \\
\hline 12. Read. Then answer the questions & & & & 1 & & & & 1 & & & 1 & 2 & & & & & 5 \\
\hline 13. Read & & & & 1 & 1 & & & & & & & & 1 & & & & 3 \\
\hline 14. Complete the table/dialogue & & & & 2 & 1 & 1 & & & & & & & & & & & 4 \\
\hline 15. Listen and choose the right picture/answer & & & & & & 1 & 3 & 2 & 2 & 1 & 2 & 1 & & 1 & & 1 & 14 \\
\hline 16. Write sentences/ a description & 1 & & & 2 & & 2 & & & & & & 2 & 1 & 2 & 1 & & 11 \\
\hline 17. Listen and answer & & & & & 1 & 2 & 1 & 1 & & & & & & & & 5 \\
\hline 18. Listen and read & & & & & & 1 & & 1 & & & & 3 & & 2 & 2 & 2 & 11 \\
\hline
\end{tabular}

The table shows that although all of the activities and tasks are under different names, they are quite similar to each other in the way learners perform them. The textbook also has some games such as 'play bingo', 'play Simon Says' or 'a picture quiz' to help learners review vocabulary in an entertaining way. The workbook states that it intends to help learners practice grammar, vocabulary and language functions introduced in the lesson in the textbook through writing and reading activities and tasks so no listening and speaking activities and tasks are introduced to learners. Moreover, it is used as homework for learners. It means all of the activities and tasks in the workbook are done at home and they are usually in forms of complete conversations, complete sentences, read then answer the comprehension questions and describe pictures. They are illustrated below. 
TABLE 2

RANGE OF ACTIVITIES AND TASKS PRESENTED IN ENGLISH 6 WORKBOOK

\begin{tabular}{|l|l|l|l|l|l|l|l|l|l|l|l|l|l|l|l|l|l|}
\hline Types of activities and tasks & \multicolumn{9}{|c|}{ Lesson } & \multicolumn{1}{|c|}{} \\
\hline & 1 & 2 & 3 & 4 & 5 & 6 & 7 & 8 & 9 & 10 & 11 & 12 & 13 & 14 & 15 & 16 & Totals \\
\hline 1. Complete the sentences & 2 & 1 & 4 & 2 & 2 & 1 & 1 & 2 & & 2 & & 1 & 1 & 1 & 2 & 1 & 23 \\
\hline 2. Complete the dialogues & 4 & 2 & 2 & 1 & & & 2 & & & & 3 & & & 3 & 1 & & 18 \\
\hline 3. Write a dialogue based on the previous one & 2 & & 1 & & & & 3 & & & & 1 & & & & 1 & & 8 \\
\hline 4. Rearrange the dialogues & 1 & & & & & & & & & & & & & & & & 1 \\
\hline 5. Write sentences & 1 & 1 & & 3 & 3 & 2 & 1 & 3 & 1 & & 1 & 1 & 1 & 2 & & 1 & 21 \\
\hline 6. Match the words/sentences with the correct pictures & 1 & & & & 1 & 1 & & & & & & & & 1 & & 1 & 5 \\
\hline 7. Answer the questions & & 1 & 1 & 1 & 1 & 2 & 1 & 1 & & 3 & & 4 & 2 & 1 & 1 & 1 & 20 \\
\hline 8. Read. Then answer the questions & & & 1 & & & & 1 & 1 & & & & 1 & & & & & 4 \\
\hline 9. Write a description & & & & & & & 1 & & 1 & & & 1 & 2 & & 1 & & 6 \\
\hline 10. Sentence building & & & & 2 & & & & & & 1 & & 1 & & & & & 4 \\
\hline 11. Use the correct form of the given verbs & & & & 1 & 2 & 1 & 1 & 1 & & & & 1 & & & & & 7 \\
\hline 12. Write questions for the answers & & 1 & & 2 & 2 & 1 & & 2 & & & & 2 & & & 3 & & 13 \\
\hline 13. Complete the table & & & & & 2 & & & & & & & & & & 1 & & 3 \\
\hline 14. True-false exercises & & & & & & & 1 & 1 & & 1 & 1 & 1 & & & & 5 \\
\hline 15. Match words together/question and answers & & 1 & 1 & 1 & & & & & & & 1 & & 1 & 1 & & 1 & 7 \\
\hline 16. Name the objects & & 1 & 1 & & & & & & 2 & 1 & & & & & 1 & 6 \\
\hline 17. Use given information to write questions and answer & & & & & 1 & & & & & & & & & & & 1 \\
\hline 18. Gap filling & & & & & & & 1 & & & 2 & & & & & & 3 \\
\hline
\end{tabular}

The two tables above show that English 6 with its accompanying workbook provide many role-play activities and tasks, but most of them focus on accuracy (i.e., listen and repeat the dialogue, practice given dialogues with a partner, practice the dialogue with some substitutions given). In other words, there are some limits on the variety of activities and tasks in the textbook with its accompanying workbook. Although these kinds of activities and tasks may encourage learners to involve themselves in classroom activities and tasks, they fail to help learners practice the language use in real communication outside the classroom. In short, form-focused practice is the emphasis of the textbook and its accompanying workbook.

\section{B. Encouragement of Learner Interaction and Promotion of Learners' Communicative Abilities}

When scrutinizing the contents of the activities and tasks in both the textbook and workbook and the aboveillustrated examples, it seems that the activities and tasks are intended to introduce language material to learners to help them practice the four language skills. It has learners practice listening skill through 'Listen and repeat' activities, speaking through 'Practice the conversation with a partner', reading in 'Read. Then answer the questions' and writing in 'Write' activities. The level of difficulty is increasing as first learners just do the repetition then the substitution in their practice usually in pairs to complete the activity and task requirements. Finally, there are some more challenging activities or tasks which ask learners to use their real information to practice in the textbook. However, there are not enough such challenging activities and tasks for learners to practice. In the workbook the activities and tasks are similar to those in the textbook in their form. The language used for instructions which precede each activity and task is simple, clear and rather easy for learners to follow. They are short commands (Listen and repeat; Listen and repeat. Then practice with a partner; Listen and read. Then answer the questions; Complete the dialogues, etc.,)

With regard to the encouragement of learner interaction, it is affected by not only the level of difficulty, the distribution of the four language skills practice and the types but also the content of the activities and tasks. The content of activities and tasks in English 6 is related to family, school, daily activities, etc., which are considered to be very familiar to learners regardless of any social background. In addition, Tomlinson (1998) emphasizes that real communicative interaction in classroom can be achieved through information or opinion gap activities, post-listening and post-reading activities, creative writing and creative speaking activities and formal instruction. However, the textbook is deficient in many of the types of information gap and role-play activities which focus on fluency; creative writing and speaking and open-ended question discussions which help learners exchange, share information and express their opinions to engage them in truly meaningful and effective communication such as negotiation of meaning (see Table 1). This may cause the potential to be a serious problem in some teaching and learning contexts (Litz, 2006).

One more negative note on the activities and tasks in the textbook is that there is only one group work activity during the textbook. There are no activities or tasks which provide each individual member in a group with unique information that must be combined in order to complete a task to help learners practice what is called 'negotiation of meaning' as mentioned by Jacobs and Ball (1996).

When coming to post-listening and post-reading activities, English 6 often presents these activities but most of them are not presented in a communicative way. In other word, in these activities and tasks, learners just do the repetition or substitution. This means they practice under very controlled situations. These, to some extent, are good for form- 
focused practice, but according to Widdowson (1978), producing correct linguistic structures (through repetition or substitution drills as in English 6) does not guarantee an appropriate use in real-life communication. So these kinds of activities and tasks seem to help encourage interactions among learners but they do not work effectively in real communication. These are shown in the following examples:

Example 1:

B My routine

1 Read.
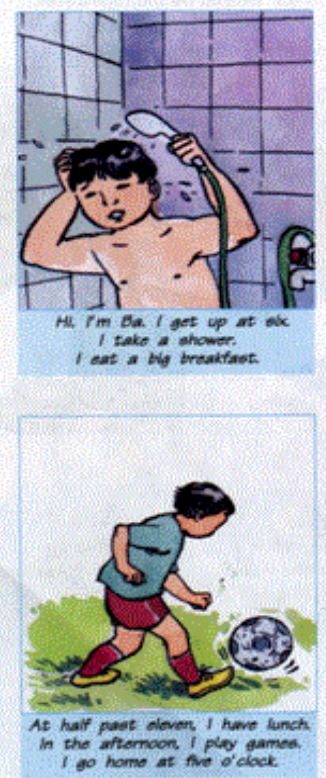

56

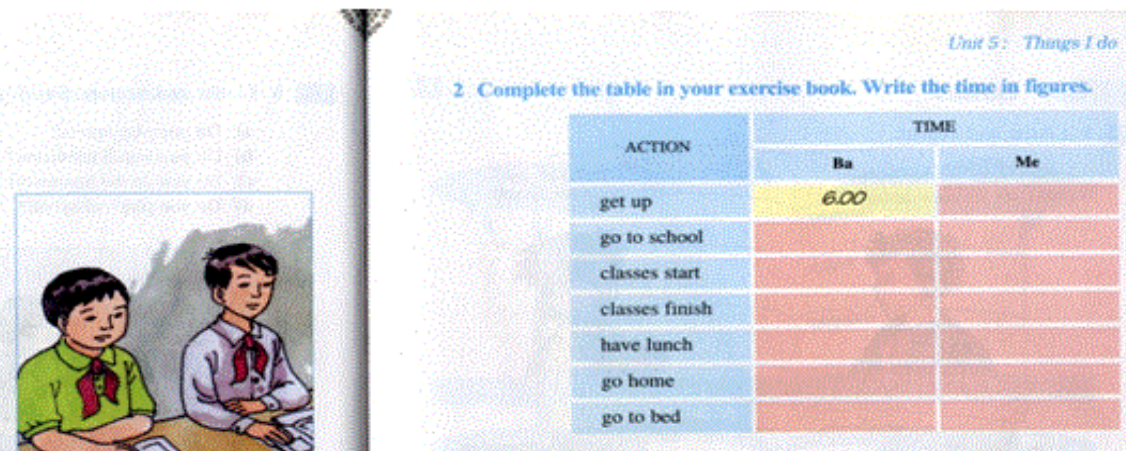

3 Practice with a partner. Use your table.

What tume does Ba get up/go to school/have classes/have lunch/go home/go to bed?

b) What time do you get up/go to school/have classes/have lunch/go bomeigo to bed?

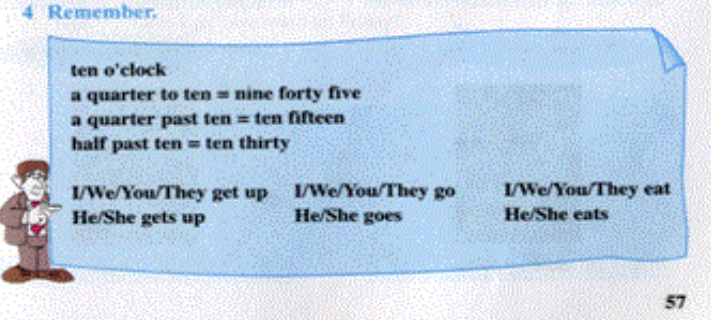

Figure 1: Illustration of activities and tasks in English 6 (Nguyen et al., 2006, pp. 56-57)

Example 2:

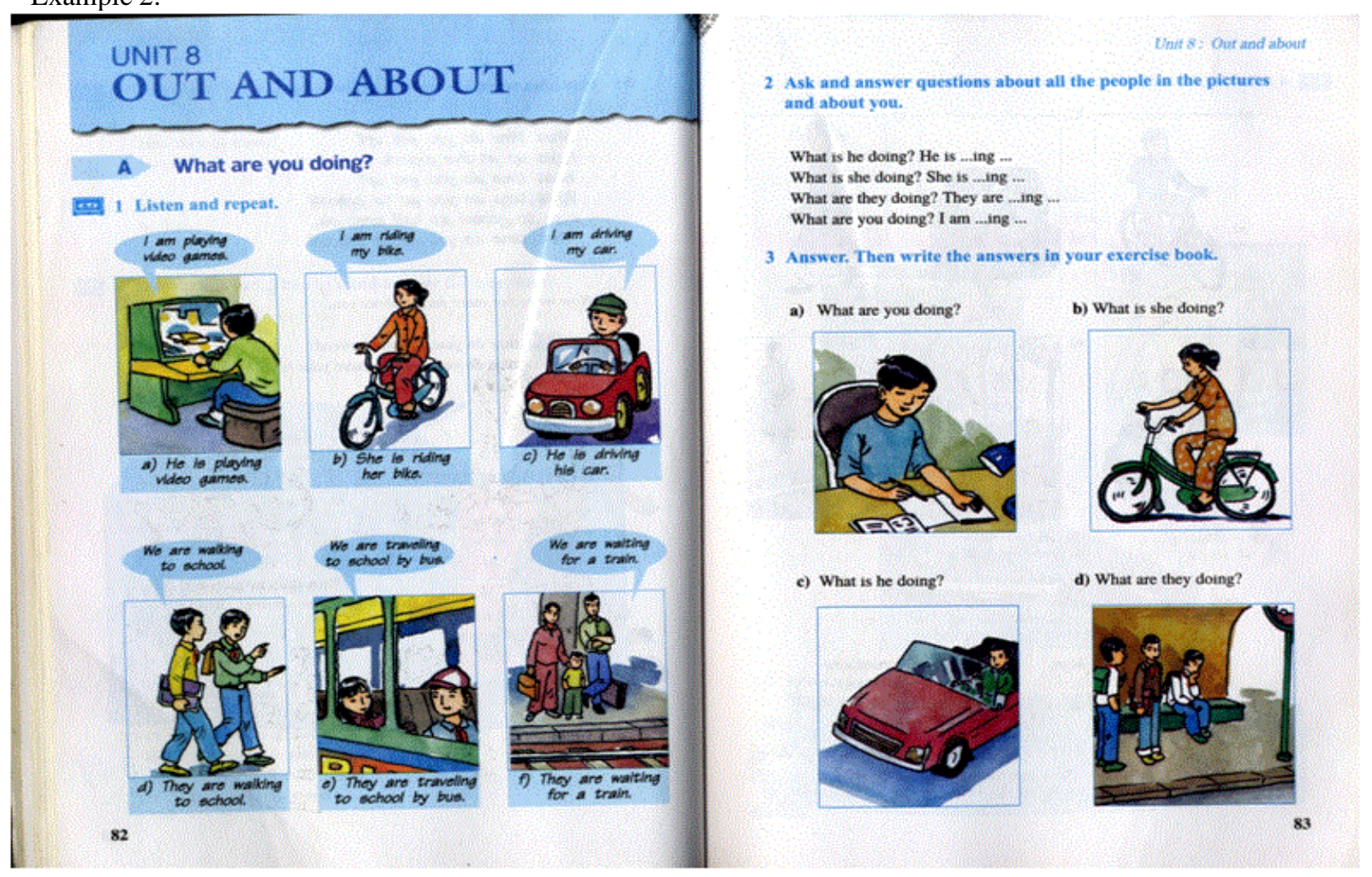




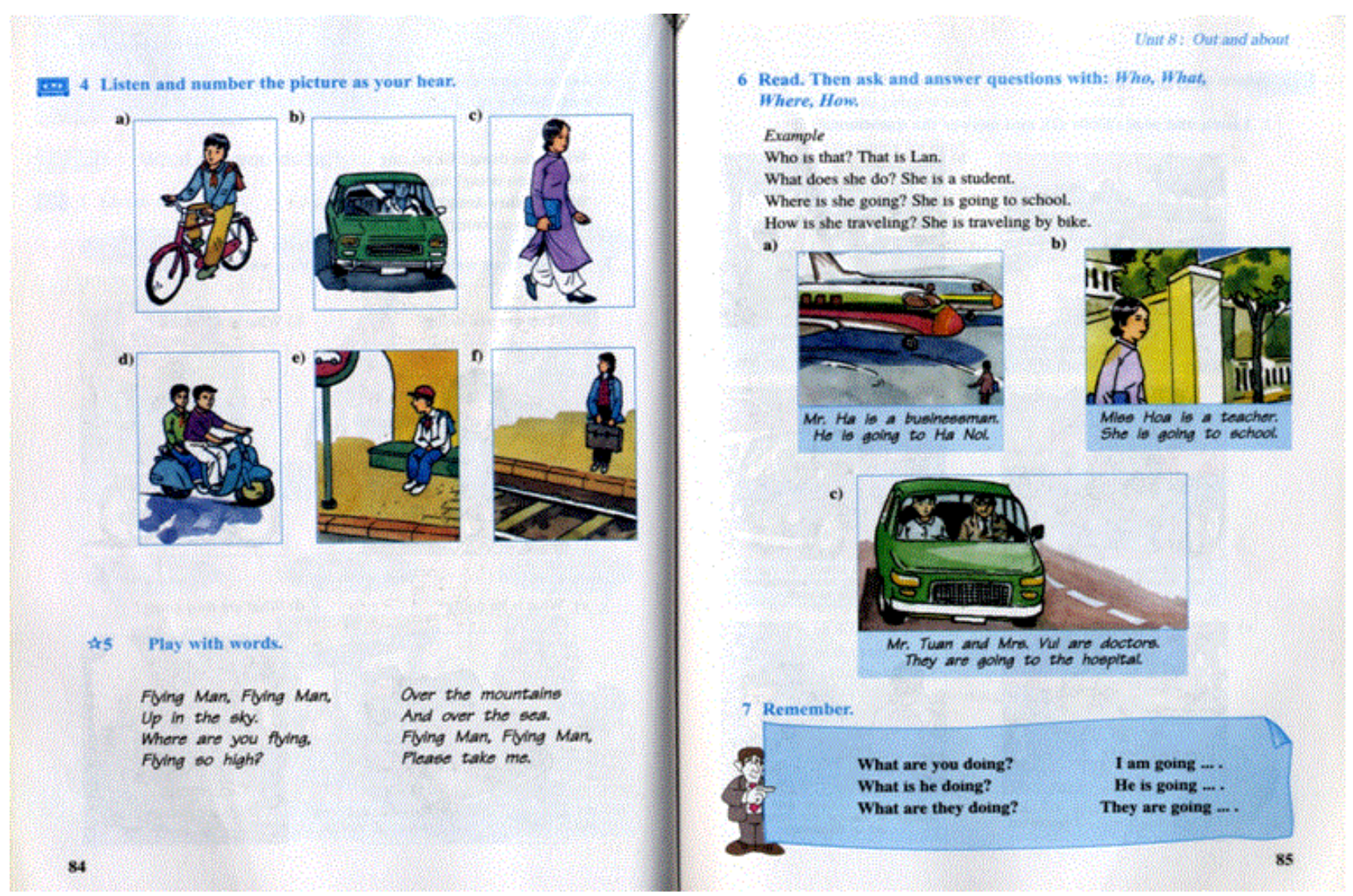

Figure 2: Illustration of activities and tasks in English 6 (Nguyen et al., 2006, pp. 82-85)

Among the four above-mentioned components of communicative competence suggested by Canale (1983), it is easy to recognize that grammatical competence could be obtained through activities and tasks in English $\mathbf{6}$ as each section in every lesson usually began with 'Listen and repeat' which actually introduces vocabulary, pronunciation and spelling, and structures to learners. Also, in this part learners have time to practice what they have been introduced to. Sociolinguistic competence, however, is not directly perceived in each activity and task. Social contexts (the place where the conversations took place, the relationship of interlocutors, etc.,) are not clearly stated, they are only recognized through pictures or topics of the lessons. One more drawback of the social contexts in the activities and tasks in the textbook is that all of them and pictures describing them are Vietnamese ones. This may cause some problems in language use when learners are in their real-life communication, especially when they use English with foreigners or outside Vietnam. The third and fourth components, discourse and strategic competence are not included in the textbook.

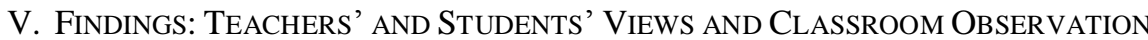

\section{A. Results of the Teachers' and Students' Evaluation on the Questionnaire}

The findings from the questionnaires for learners show that the learners thought that they had enough practice for listening, speaking, reading and writing. The percentage was as follows: $69.0 \%, 85.7 \%, 88.9$ and $70.0 \%$ respectively. The level of difficulty of them is relevant to learners as they just do the substitution in their practice usually in pairs to fulfill the requirements. Then there are some more challenging activities or tasks which ask learners to use their real information to practice in the textbook. However, there are not enough such challenging activities and tasks for learners to practice. In the workbook the activities and tasks are similar to those in the textbook in their form. The language used for instructions which precede each activity and task is simple, clear and rather easy for learners to follow. They are short commands (Listen and repeat; Listen and repeat. Then practice with a partner; Listen and read. Then answer the questions; Complete the dialogues, etc.,). This is quite similar to the findings from the questionnaires when $70.2 \%$ of learners and $75 \%$ of instructors agreed that the difficulty of the activities and tasks was relevant at learners' level. The instruction preceded each activity and task is clear and rather easy for learners to follow. It recurs many times in the textbook as well as in the workbook. Most of the learner participants $(84.1 \%)$ thought that the instructions were clear and easy for them to follow to fulfill the activities and tasks.

With regard to the encouragement of learner interaction, it is affected by not only the level of difficulty, the distribution of the four language skills practice and the types but also the content of the activities and tasks. Tomlinson (1998) emphasizes that real communicative interaction in classroom can be achieved through: 
- Information or opinion gap activities which require learners to communicate with each other and/or the teacher in order to close the gap (e.g. finding out what food and drink people would like at the class party);

- Post-listening and post-reading activities which require the learners to use information from the text to achieve a communication purpose (e.g. deciding what television programs to watch, discussing who to vote for, writing a review of a book or film);

- Creative writing and creative speaking activities such as writing a story or improvising a drama;

- Formal instruction given in the target language either on the language itself or on another subject. (Tomlinson, 1998, p. 15)

Based on the above-mentioned issues, it seems that English 6 provides many of role-play activities and tasks, but most of them focus on accuracy (i.e., listen and repeat the dialogue, practice given dialogues with a partner, practice the dialogue with some substitutions given). The activities and tasks are deficient in many of the types of information gap and role-play activities which focus on fluency; creative writing and speaking and open-ended question discussions which help learners exchange, share information and express their opinions to engage them in truly meaningful and effective communication such as negotiation of meaning (see Table 1). This may cause the potential to be a serious problem in some teaching and learning contexts (Litz, 2006).

\section{B. Classroom Observation}

\section{Description of the observed classrooms}

Classroom observation was conducted to see the extent to which the textbook and its supporting resources influenced the teaching process and the extent to which it is suitable for the context. The teaching and learning context in this research is rather specific, as mentioned in 7.1. The classroom observation was conducted by the researcher and two other teachers at each school where the demonstration teaching took place.

Regarding the equipment in each classroom, all of the schools observed were similar. Nguyen, (2015) describes, each classroom was about $5 \mathrm{~m} \times 7 \mathrm{~m}$. There was a desk and a chair for the teacher located near the chalkboard. Two or four rows with six lines of tables and chairs were arranged in each classroom. There were no other props to assist the teaching and learning (computer, OHP, video, etc.) in the classrooms. If teachers wanted to use a cassette player, they had to take it from the school library or the teaching staff room. Two or four students shared a table and sat facing the chalkboard. The number of students in each class varied according to the area. In cities, there are up to 50 students in one class, but in rural areas there were some classes with fewer than 30 students. The classroom size, as mentioned above, became overcrowded when there were more than 30 students present. The number of students in the observed classes varied. Due to the number of students and the layout of the classroom, it was not easy to organize group work.

\section{Classroom procedures}

With reference to the eight demonstration teaching periods, five of the teachers began with checking the previous lesson. The other three began with warm-up and lead-in for the new lesson. In checking the previous lesson, the majority followed what had been guided in the seminars, focusing on the oral test, with two asking students to perform the dialogue in pairs in front of the class. The other two used the pictures in the textbook to ask students to describe people (people's jobs and appearance). In the remaining period, the teacher asked students to write some sentences to describe people's appearance in the pictures and in that way students were checked for their memorization or recitation as both the dialogues and pictures had already appeared in the previous lesson.

In conducting new lessons, all of the teachers seemed to follow the PPP technique consistently. In the presentation stage, they all utilized the pictures in the textbook and the accompanying set of pictures to introduce new language material to their students. However, they asked questions of the students, based on the pictures. In fact, they did not give the students time to exchange their knowledge with each other to answer the questions. None of the teachers posited questions or created situations for students to work together. In other words, teachers did not effectively elicit or exploit their students' prior knowledge about the study topic to encourage their contribution to the lesson. There was one period at a school in an urban area when the teacher took his students to the language lab to conduct a lesson there. This lab, in fact, was similar to other classrooms, except that it had a screen and a computer. Although the teacher used Powerpoint to conduct his lesson, this period was similar to others. One difference was that the teacher, instead of using the pictures, scanned and put them on slides, with some instructions copied from the textbook, to draw his students' attention to the lesson. Below are some illustrations which illustrate the presentation stage used by the majority of teachers in the demonstration teaching periods.

In teaching Lesson 10, Part B: Food and drink, the teacher asked his students, 'What do you usually eat?' then appointed some students to answer the questions. After some responses from the students, he used the pictures on page 108 to present new words to his students. He then read each new word, and asked them to repeat them as a group and individually. The structure was introduced to the students after they had finished practicing the vocabulary.

In teaching Lesson 11, Part A: 'At the store', the teacher used the pictures on page 114 to ask students to name the objects in the pictures in Vietnamese. She then introduced English equivalents, reading them and asking the students to repeat them as a group and individually. Having asked students to practice the vocabulary, she continued introducing the dialogue to her students, read it and asked the students to repeat it as a group chorally.

In the two illustrations above, we can see that the teachers were mostly active and the students were passive listeners who sometimes contributed to the lesson by answering the teachers' questions. Also, the teachers were at the center and 
talked most. In the practice stage, it was somewhat different as the students talked much more than the teachers. The students were asked to practice the structure or conversation they had just studied, including some substitution drills as in the textbook, with their partners. At the end of this stage, the teachers asked some pairs to perform in front of the class. All teachers conducted this stage in the same way, following the guidance in the textbook without any supplement. This seemed to emphasize the control of the teachers and the textbook over their students in order to achieve accuracy through repetition and substitution drills.

In the textbook there are a few activities and tasks involving production, so if teachers want to proceed to the production stage in the classroom, they have to create practical situations themselves. Among the eight demonstration teaching periods, five of the teachers stopped at the practice stage, after their students had finished their practice with some substitutions. The other three proceeded to the production stage, and conducted it as follows:

In Lesson 12, Part B: 'At the canteen', after the students had finished practicing asking and answering the price of the given items in the pictures, the teacher asked them to practice in pairs to ask and answer questions about the price of items they possessed or some things they wanted to buy. Then he asked some pairs to perform in front of the class.

In Lesson 10, Part A: 'How do you feel?' After the students finished working in pairs, asking and answering questions about the feelings of people in the pictures, the teacher asked them to work in groups of three. One performed a mine to describe a feeling and the other two asked and answered about the other student's feeling. Some groups were then asked to perform in front of the class.

The two above descriptions show attempts by some teachers to create real opportunities for students to use the target language in communication in classroom situations. These are thought to help students develop confidence about their use of English in real life communication, especially when in similar situations to those practiced.

One more common element, together with that of PPP, was that all conducted their grammar presentation in a deductive way. They began with the presentation of the marker sentence, which contained the structure or grammatical point, summarized the grammatical points in formulas, and then explained the formation and usages to their students. After the explanation, they gave more examples to illustrate it. This way is considered to save time for teachers as they explain everything to their students. However, students do not have much opportunity to make contributions to the lesson in situations like this so they become quite passive learners.

\section{Consensus on the classroom observation sheet}

Regarding the lesson summary sheets, the data obtained from the observers is presented below.

In the teacher speaking time, there were six out of the eight periods in which the teachers spent some of the time talking (30\%) in the class. Students were encouraged to work mainly with their partners to practice speaking in the form of role-play in the given dialogues (repetition and substitution) and free practice/production. In the remaining two, teachers spent most of the time speaking (over 70\%) in the class, with little time for students to work together to practice speaking.

Moving to command of English, four were thought to have a strong command of English and the other four had a fairly strong command. Seven used the mother tongue some of the time to translate language material. One of them used mother tongue most of the time: that is, after using English he translated into Vietnamese. For the instructions, regardless of whether the teachers used English or Vietnamese or combined both English and Vietnamese, their instructions were assessed to be clear enough for students to follow.

Although students' talking time occupied some of the time in the class, students used English most of the time, as they were asked to practice with their partners or perform a task in front of the class. However, their talk seemed to be restricted to repetition or substitution.

In terms of the degree of textbook use and the use of teaching aids, the majority of the teachers (seven out of eight) used only the textbook and followed it most of the time. Only one of them supplemented the teaching period with a creative task. In fact, this teacher created a free practice (production) stage and asked students to undertake it. As the lessons were mostly based on the textbook, none used group work in their teaching. Six of them used pair work and the rest used individual work only. The use of teaching aids in the classroom was thought to be appropriate by the observers, but a little bit boring, as they all used the set of larger pictures than those in the textbook. Teaching aids were used to present new language material, meanings of words and controlled practice. Three used a cassette player to teach listening, but mostly for the purpose of presentation, not as the focus of the lesson.

In general, classroom observation indicated that the teachers followed the textbook and the teacher's manual most of the time in the classroom. There was little creativity applied to the teaching to make the lesson more interesting and flexible. The students' use of the target language was limited as they practiced it mostly in controlled situations presented in the textbook. Their prior knowledge of the lesson was not exploited effectively to enable students to contribute more fully to the lesson. Both the textbook and the way the teachers conducted the lesson seemed to follow PPP. However, the production stage was limited, so students had few opportunities to practice the target language communicatively.

\section{Suggestions for Improvement from the Teachers and Students}

The strengths weaknesses of the activities and tasks in English $\mathbf{6}$ and its accompanying workbook have been recognized in the previous parts. The suggestions for improving the activities and tasks in them were collected from the questionnaires for both the instructors and learners. Among eight teachers and 126 students participated in the research, 
six suggestions were given by five of the instructors (63\%) and 34 learners (27\%) gave 34 suggestions for improvement. They are combined and presented as follows.

With regard to the suggestions from the students for improvement, their 34 suggestions can be divided into four themes. The first theme is the layout of the activities and tasks. The majority of the learners' suggestions (52.9\%) wanted to have space after each activity and task to finish them directly in their textbook if long answers are required. The reason for this focus is that they may feel it easier and more comfortable to have the answers directly after the questions. The following sentences are cited from their suggestions: 'We do not have any space to write down our answers in some activities and tasks.' (English translation), 'Space should be provided after the activities and tasks which require long answers.' (English translation). The second theme is types of the activities and tasks. 26.5\% of the learners' suggestions wanted to have more activities and tasks under game types (i.e., Play with words, Picture quiz, etc.,), 'I want more activities and tasks in which we can study through games so that we can compete with each other.' (English translation). The third theme focused on the level of difficulty. 17.6\% of them wanted the activities and tasks to be easier to make sure slow learners could practice and finish them. The remaining percentage also focused on types of the activities and tasks, but they suggested having activities and tasks in which they work in groups to practice with each other. It can be inferred from the suggestions that they mainly focus on form of the activities and tasks. This is quite parallel with Cameron's (2001) theory on young learners of English. Students at that age, according to her, are lively and enthusiastic but can lose interest easily. So they need various types of activities and tasks to help them avoid turning off.

The six suggestions from the instructors in the questionnaire seem to support the students' ones. In fact, they are similar to those of the students' in field of the themes they focused. Three suggestions asked for more group work activities as they would help maintain learners' interest and make them involve in classroom interaction more. One of them wrote that, 'There should be group work activities to create opportunities for learners to work with many different members in their class.' (English translation). One suggested adding more 'free practice' activities to help learners familiarize themselves in real communication writing that, 'I think the authors should make more activities and tasks in which learners can use their real information to communicate with each other.' (English translation). Two suggestions focusing on the level of difficulty from the instructors were similar to those of the learners'. One of them mentioned that, 'Some of my students cannot finish some activities or tasks, they should be a little bit easier.' (English translation).

The suggestions for improvement collected in the interviews with the teachers were more diverse. They focused on types of activities and tasks, level of difficulty and distribution of four language skills. Three suggestions asked for easier tasks to motivate weak students to involve in classroom activities. Six of them wanted to have more group activities and tasks which can help students share their opinions with each other. In other words, they wanted students to talk and exchange their ideas to each other in order to complete an activity or a task. The remaining focused on the supplement of specific skill practicing, but the specific skills they suggested were different from each other. One asked for more reading activities and tasks, one for listening and writing, one for speaking and the last one just asked for more tasks.

In general, the above-mentioned suggestions seem to be very general and do not focus much on the content of the activities and tasks. Although the activities and tasks are deficient in information gap; role-play; creative writing and speaking and open-ended question discussions, no suggestions related to these issues were made. In addition, there is also lack of free practice and productive practice in which students produce something new from what they have learnt.

\section{CONCLUSIONS}

In short, this paper has indicated that textbooks do not always provide adequate source of activities and tasks for learners to practice to develop their communicative competence.

Another argument this study has mentioned is that not all textbook developers can introduce activities and tasks which introduce more authentic material and contexts and encourage learner interaction among learners in classroom to prepare them for effective communication in real life.

From the above conclusions, Nguyen (2015) suggests that:

In teaching, teachers should:

1. Be flexible at the presentation stage when introducing new language material, to make it more open with more pupil involvement, allowing pupils to recall their background knowledge.

2. Extend the practice stage in each section to free practice in which pupils can use the target language more freely after controlled practice. This provides learners with opportunities to use the target language.

3. Use additional material such as picture stories, comic strips, etc. in some units to motivate learners to study, as young learners at this age should study a foreign language through interesting visual aids and activities (Cameron, 2003).

In research:

The present research study focused on the context of English language teaching and learning in specific provinces (Mekong Delta) of Vietnam. It also involves only theoretical evaluation and evaluation voices from teachers and students only. 
The voices of the textbook authors, parents and other stakeholders (teacher trainers, school head teachers, etc.) are also important in the textbook evaluation process, so they should be involved in further research.

Further research should also use focus group interviews, discussions or informal talks for both teachers and students to enhance the quality of the data.

\section{REFERENCES}

[1] Alptekin, C. (2002). Towards intercultural communicative competence in ELT. ELT Journal, 56(1), 57-64.

[2] Awasthi, R. J. (2006). Textbook and its evaluation. Journal of NELTA, 11(1-2), 1-10.

[3] Bell, J. and Gower, R. (1998). Writing course materials for the world: a great compromise, in Tomlinson (ed.) Materials Development in Language Teaching. Cambridge, Cambridge University Press, 116-129.

[4] Block, D. (1991). Some thoughts on DIY materials design. ELT Journal, 45(3), 211-217.

[5] Cameron, L. (2001). Teaching Languages to Young Learners. Cambridge, Cambridge University Press.

[6] Canale, M. (1983). On some dimensions of language proficiency, in Oller (ed.) Issues in Language Testing Research. Rowley, MA: Newbury House, 332-342.

[7] Canale, M., and Swain, M. (1980). Theoretical bases of communicative approaches to second language teaching and testing. Applied linguistics, 1(1), 1-47.

[8] Chomsky, N. (1965). Aspects of the Theory of Syntax. The Massachusetts Institutes of Technology.

[9] Cotterall, S. (2000). Promoting learner autonomy through the curriculum: Principles for designing language courses. ELT Journal, 54(2), 109-17.

[10] Crookes, G and Suan, M. G. (1993). Tasks in a Pedagogical Context: Integrating Theory and Practice. Clevedon: Multilingual Matters.

[11] Duggan, S. (2001). Educational reform in Vietnam: A process of change or continuity? Comparative Education, 37(2), $193-212$.

[12] Ellis, R. (1997). The empirical evaluation of language teaching materials. ELT Journal, 51(1), 36-42.

[13] Ellis, R. (2005). Planning and Task Performance in a Second Language. Amsterdam, John Benjamins Publishing House.

[14] Hymes, D., (1979). Individual Differences in Language Ability. Academic Press New York. NY.

[15] Jacobs, G. M., and J., Ball. (1996). An investigation of the structure of group activities in ELT coursebooks. ELT Journal, 50(2), 99-107.

[16] Littlejohn, A. P. (1992). Why Are ELT Materials the Way They Are? Unpublished PhD thesis. Lancaster: Lancaster University.

[17] Litz, R. A. D. (2002). Textbook evaluation and ELT management: A South Korean Case Study. Asian EFL Journal, 48(1), 553.

[18] Long, M.H. (1990). Task, group, and task-group interaction in S. Anivan (ed.). Language Teaching Methodology for the Nineties. SEAMEO Regional Language center.

[19] McDonough, J. and C. Shaw. (1993). Materials and Methods in ELT. Oxford: Blackwell.

[20] McGrath, I., (2002). Materials Evaluation and Design for Language Teaching. Edinburgh, Edinburgh University Press Ltd.

[21] Maley, A., (1998). Squaring the circle - reconciling materials as constraint with materials as empowerment, in Tomlinson, B. (ed.) Materials Development in Language Teaching (pp. 279-94). Cambridge, Cambridge University Press.

[22] Nguyen, C. T. (2013). Communicative Language Testing: Do School Tests Measure Students' Communicative Competence. FLLT conference proceedings, Language Institute Thammasat University, Thailand. http://litu.tu.ac.th/FLLT2013/www.fllt2013.org/private_folder/Proceeding/856.pdf

[23] Nguyen, C. T. (2015). An Evaluation of the Textbook English 6: A case study from secondary schools in the Mekong Delta Provinces of Vietnam. Unpublished PhD thesis. The university of Sheffield.

[24] Nguyen, M. T. T. (2011). Learning to communicate in a globalized world: to what extent do school textbooks facilitate the development of intercultural pragmatic competence? RELC Journal, 42(1), 17-30.

[25] Nguyen, V. L., Nguyen, H. D., Than, T. L. N. \& Nguyen, Q. T. (2006). English 6. (4 ${ }^{\text {th }}$ Ed.). Ha Noi, The Educational Publishing House.

[26] Nunan, D. (2003). The impact of English as a global language on educational policies and practices in the Asia-Pacific region. TESOL Quarterly, 37(4), 589-613.

[27] Rea-Dickins, P. and Germaine, K. (1994). Evaluation. Oxford, Oxford University Press.

[28] Sheldon, L. (1988). Evaluating ELT textbooks and materials. ELT Journal, 42(4), 237-46.

[29] Skehan, P., (1998). A Cognitive Approach to Language Learning. Oxford, Oxford University Press.

[30] Thomas, A. M., (1987). Classroom Interaction. Oxford, Oxford University Press.

[31] Tomlinson, B., (1998). Materials Development in Language Teaching. Cambridge, Cambridge University Press.

[32] Tomlinson, B. (2003). Introduction: Are materials developing? in B. Tomlinson (ed.). Developing Materials for Language Teaching. New York, Continuum, 1-11.

[33] Widdowson, H.G. (1978). Teaching Language as Communication. Oxford, Oxford University Press.

[34] Widdowson, H. G., (2003). Defining Issues in English Language Teaching. Oxford, Oxford University Press.

Cang Trung Nguyen is now a lecturer at the Faculty of Foreign Languages - Kien Giang University - Vietnam. He holds an MA in Applied Linguistics from La Trobe University - Australia and a PhD in Applied Linguistics at The University of Sheffield - UK. He worked as a teacher trainer at Kien Giang Teacher Training College - Vietnam for over ten years before moving to Kien Giang University and has worked there since 2015 as a lecturer of English. 
Diem Thi Kieu Le holds an MA in Educational Management from Hanoi University of Education - Vietnam. She worked as a teacher trainer at Kien Giang Teacher Training College - Vietnam for over 15 years. Since 2015 she moved to Kien Giang University and has been working as a lecturer. 